\title{
Productive life span and resilience rank can be predicted from on-farm first-parity sensor time series but not using a common equation across farms
}

\author{
I. Adriaens,,${ }^{1,2,3 *} \odot$ N. C. Friggens, ${ }^{4}$ W. Ouweltjes, ${ }^{5} \odot$ H. Scott, ${ }^{3}$ B. Aernouts, ${ }^{1} \odot$ and J. Statham ${ }^{3} \odot$ \\ ${ }^{1}$ Department of Biosystems, Biosystems Technology Cluster, Katholieke Universiteit Leuven, Campus Geel, 2440 Geel, Belgium \\ ${ }^{2}$ Department of Biosystems, Division Mechatronics, Biostatistics and Sensors, Katholieke Universiteit Leuven, 3001 Leuven, Belgium \\ ${ }^{3}$ RAFT Solutions Ltd., Mill Farm, Ripon HG4 2QR, United Kingdom \\ ${ }^{4}$ UMR Modélisation Systémique Appliquée aux Ruminants, INRAE, AgroParisTech, Université Paris-Saclay, 75005, Paris, France \\ ${ }^{5}$ Wageningen Research, Breeding and Genomics, 6708PB Wageningen, the Netherlands
}

\begin{abstract}
A dairy cow's lifetime resilience and her ability to recalve gain importance on dairy farms, as they affect all aspects of the sustainability of the dairy industry. Many modern farms today have milk meters and activity sensors that accurately measure yield and activity at a high frequency for monitoring purposes. We hypothesized that these same sensors can be used for precision phenotyping of complex traits such as lifetime resilience or productive life span. The objective of this study was to investigate whether lifetime resilience and productive life span of dairy cows can be predicted using sensor-derived proxies of first-parity sensor data. We used a data set from 27 Belgian and British dairy farms with an automated milking system containing at least $5 \mathrm{yr}$ of successive measurements. All of these farms had milk meter data available, and 13 of these farms were also equipped with activity sensors. This subset was used to investigate the added value of activity meters to improve the model's prediction accuracy. To rank cows for lifetime resilience, a score was attributed to each cow based on her number of calvings, her 305-d milk yield, her age at first calving, her calving intervals, and the DIM at the moment of culling, taking her entire lifetime into account. Next, this lifetime resilience score was used to rank the cows within their herd, resulting in a lifetime resilience ranking. Based on this ranking, cows were classified in a low (last third), moderate (middle third), or high (first third) resilience category within farm. In total, 45 biologically sound sensor features were defined from the time series data, including measures of variability, lactation curve shape, milk yield perturbations, activity spikes indicating es-
\end{abstract}

Received October 31, 2019.

Accepted March 21, 2020.

*Corresponding author: ines.adriaens@kuleuven.be trous events, and activity dynamics representing health events (e.g., drops in daily activity). These features, calculated on first-lactation data, were used to predict the lifetime resilience rank and, thus, to predict the classification within the herd (low, moderate, or high). Using a specific linear regression model progressively including features stepwise selected at farm level (cutoff $P$-value of 0.2 ), classification performances were between 35.9 and $70.0 \%(46.7 \pm 8.0$, mean $\pm \mathrm{SD})$ for milk yield features only, and between 46.7 and $84.0 \%$ $(55.5 \pm 12.1$, mean \pm SD) for lactation and activity features together. This is, respectively, 13.7 and $22.2 \%$ higher than what random classification would give. Moreover, using these individual farm models, only 3.5 and $2.3 \%$ of cows were classified high when they were actually low, or vice versa, whereas respectively 91.8 and $94.1 \%$ of wrongly classified animals were predicted in an adjacent category. The sensor features retained in the prediction equation of the individual farms differed across farms, which demonstrates the variability in culling and management strategies across farms and within farms over time. This lack of a common model structure across farms suggests the need to consider local (and evidence-based) culling management rules when developing decision support tools for dairy farms. With this study we showed the potential of precision phenotyping of complex traits based on biologically meaningful features derived from readily available sensor data. We conclude that first-lactation milk and activity sensor data have the potential to predict cows' lifetime resilience rankings within farms but that consistency between farms is currently lacking.

Key words: resilience, precision phenotyping, prediction model, longevity, precision livestock farming

\section{INTRODUCTION}

Increasing the longevity of dairy cows is key for the dairy sector's sustainability in the 3 dimensions put 
forward by the United Nations during the World Summit on Societal Development in 2005. Cows with a long productive life span typically exhibit good reproductive performance, few health problems, and efficient and consistent milk production. A dairy cow typically only starts to make profit for the farmer during her second lactation, and she reaches her full production potential as late as in her third lactation (Cabrera, 2018). Early culling and short longevity thus clearly have a negative influence on the economic efficiency of the herd. More importantly, longevity, along with optimizing the ratio between the productive and non-productive life, is also crucial for the fulfillment of societal demands and to reduce the environmental impacts of the sector (van Knegsel et al., 2014).

One step toward optimization of farm management with respect to longevity would be the identification of animals that have a high probability of completing several lactations, or, more specifically, that are "resilient." Resilient animals can be considered as animals that avoid early culling by coping well with the farm's management conditions. These animals reproduce easily, produce consistently, and react well to imposed challenges and (physiological) stress (Ahlman et al., 2011). Correct and timely identification of resilient animals would allow for optimization of breeding, treatment, and culling decisions, selecting cows that thrive in their specific farm environments. Today, many breeding decisions are still made based on emotion and habit, with a significant lack of evidence about how the animals perform on farm. For example, for breeding new replacement heifers, it might be valuable to use more expensive advanced breeding techniques (sexed semen, embryo transfer). In this context, the performance, expected longevity, and resilience of the dam may be key to justifying these techniques and making them profitable. Also, culling and treatment decisions are often made in a similar emotional fashion. Intelligent use of antimicrobials in the livestock sector is critical, and antimicrobial budgets are restricted (de Jong et al., 2018). Proper prediction of longevity and resilience can help improve culling and treatment decisions, as this would allow for the objective substantiation of decisions on which animals are worth treating with antimicrobials and which animals are better culled than treated. This can contribute to the herd efficiency and sustainable production metrics on farm.

Optimized efficiency on farm would require that the lifetime resilience of an animal be predicted as soon as possible. Genetic indicators for lifetime resilience are not yet available, as phenotypic information on this complex trait is lacking. Nevertheless, recent technological developments have led to increased implemen- tation of sensor systems and automation to improve the herd management and reduce labor requirements (Steeneveld and Hogeveen, 2015). In addition to the detection of health problems and fertility events, many of these sensor systems also have the potential to provide targeted information about other, more complex traits (Friggens and Thorup, 2015). In this study, we hypothesized that common sensor data, such as milk production and activity time series, can be used to predict a complex trait such as lifetime resilience. Simultaneously, additional benefits of these technologies will be generated from the calculation of precision phenotypes and their use for the characterization of overall and relative performance of animals within the farm context and compared with herdmates (Royal et al., 2000; Tenghe et al., 2015; Sorg et al., 2017). Accordingly, when sensor data can be used to this purpose, selection of animals on these more complex traits becomes possible, which, when combined with the genetic merit of each animal, can boost future breeding efforts at farm and population levels (König and May, 2019).

To use sensor data for the prediction of lifetime resilience, such that it can be used for both decision support and precision phenotyping, we propose to derive biologically meaningful proxies for the cow's physiological status from the high-frequency milk yield and activity dynamics provided by commercially available sensor systems. It has previously been shown that each change in feed intake or energy allocation (e.g., for an immune response) may result in yield perturbations (Ben Abdelkrim et al., 2019), and, thus, the milk yield dynamics mirror the animal's physiological status. Similarly, activity dynamics reflect potential estrus and the more general behavioral responses of the cows to physiological and environmental stress (Rutten et al., 2013). Because of the link between health and fertility performance and longevity and culling, the proposed concept is that, through characterization of these dynamics, it will be possible to predict their lifetime resilience.

This study aimed at developing meaningful milk yield and activity features from first-lactation sensor time series and combining these features into a model capable of predicting the lifetime resilience of the cows on each farm. This model could be used to help farmers identify animals that cope well with their specific farm contexts - for example, to aid breeding (e.g., dam selection for sexed semen, embryo transfer, or the use of a beef sire) or culling decisions as early as after the first lactation. This would allow time to make decisions that directly contribute to the farm's efficiency by selecting animals that perform well on that particular farm. 


\section{MATERIALS AND METHODS}

\section{Data Collection and Selection}

Available Data. Software backups of the farm management system were collected on, respectively, 34 and 42 Belgian and British farms that use an automated milking system (AMS). From this database, 27 farms were selected based on (1) the accessibility and reliability of at least $5 \mathrm{yr}$ of contiguous data and (2) the availability of daily milk yield at individual cow level. The time period covered by these data varied between 2005 and 2019. All 27 farms had AMS either from Lely (Lely Industries N.V., Maasluis, the Netherlands; $\mathrm{n}=16$ ) or from DeLaval (DeLaval International, Tumba, Sweden; $\mathrm{n}=11$ ). On average, 2.4 lactations were recorded per cow's life. All farms had intensive production systems, with cows kept indoors and fed with both forage and concentrates. Other management practices differed among herds but were not further documented in the software backup files of the farm management system.

All data tables were extracted from the restored backup files of the AMS software system using SQL Server Management Studio (Microsoft Corp., Redmond, WA). The further data mining, pre-processing, and merging of these data tables and the rest of the analyses described below were performed in Matlab R2017a (The MathWorks Inc., Natick, MA). Both the full data set of 27 farms all having daily milk records (data set 1, DS1) and a subset of 13 farms also having daily activity data available (data set 2 , DS2, all milked by a Lely AMS) were used for this study. An overview of the characteristics of both data sets is given in Table 1.

Cow Selection. After extraction of data tables, individual cows on each farm were selected based on the availability of sensor data for their entire lifetime production. Because exact culling dates were not always available, we elected to apply a criterion to discriminate between cows that likely had been dried off toward the end of the time span covered by the data set available for that farm (not to be included in the analysis) or removed from the herd (to be included in the analysis). For each farm, the $95 \%$ confidence interval (CI) of the average dry period length was calculated. If the last milk record was before the end of the data set minus the upper 95\% CI boundary, that cow had a 97.5\% chance of having been removed from the herd, and she was included. Accordingly, only cows that met this criterion and for which the date of first calving was within the time span of the available data for that farm were selected. An overview of the characteristics of this selection is provided in Table 1 . Data set 1 consisted of 3,754 unique cows and 9,395 unique lactations, and DS2 included 2,075 cows with 5,286 lactations. Per farm, respectively, 24 to 308 cows $(139 \pm 82$, mean \pm SD) with, in total, 44 to 799 lactations $(348 \pm 229)$, and 57 to 308 cows $(160 \pm 84)$ with 113 to 799 lactations (407 $\pm 264)$ were selected for DS1 and DS2.

Sensor Data. The milk yield sensor data were recorded by the AMS using ICAR-approved milk meters as integrated in the Lely and DeLaval robots. The available activity sensor data were recorded by Lely neckmounted activity sensors and consisted of raw 2-hourly measures of acceleration, but no further details of the individual sensor systems were available. For this study, the 2-hourly measures were summed up per day (midnight to midnight) to obtain time series of single daily activity records. Although in this study the raw data were all similar, with 2 -hourly values varying between 0 and 300, the presented methodology is independent of the actual raw values and can be applied on all measures of activity for which daily records are available as long as they represent the behavioral changes of the cows linked with estrous and health events.

\section{Calculation of Lifetime Resilience Ranking}

This study aimed at developing a model for predicting lifetime longevity and resilience using high-frequency sensor data. To this end, we considered the "lifetime

Table 1. Overview of the available data sets; data set 2 (DS2) is a subset of data set 1 (DS1) for which daily activity data were available in addition to milk meter data

\begin{tabular}{lcc}
\hline & $\begin{array}{c}\text { DS1 } \\
\text { Descriptor }\end{array}$ & $\begin{array}{c}\text { DS2 } \\
\text { Average } \pm \text { SD [range] }\end{array}$ \\
\hline No. of days data per farm & $3,001 \pm 828[1,830-4977]$ & $3,020 \pm 815[1,837-4,101]$ \\
No. of cows in total & 3,754 & 2,075 \\
No. of cows per farm & $139 \pm 82[24-308]$ & $160 \pm 94[57-308]$ \\
No. of lactations in total & 9,395 & 5,286 \\
No. of lactations per farm & $348 \pm 229[44-799]$ & $407 \pm 264[113-799]$ \\
Age at first calving per farm (yr) & $2.2 \pm 0.1[2.0-2.4]$ & $2.2 \pm 0.1[2.0-2.3]$ \\
Average 305-d milk yield per farm (kg) & $9,557 \pm 1007[7,931-11,739]$ & $9,691 \pm 1,061[8,244-11,739]$ \\
Average calving interval per farm (d) & $407 \pm 16[377-433]$ & $403 \pm 15[377-432]$ \\
Average dry period length per farm (d) & $56 \pm 13[35-91]$ & $59 \pm 16[35-91]$ \\
\hline
\end{tabular}


resilience of a cow" as "the cumulative result of her ability to recalve (and thus, to extend her productive life span) supplemented with secondary corrections for age at first calving, calving intervals, 305-day milk yield, health events and number of inseminations" (Friggens and De Haas, 2019). This definition was agreed upon in the EU Horizon 2020 GenTORE Consortium, consisting of researchers, animal experts, veterinarians, technology suppliers, and geneticists, and is further detailed in Friggens and De Haas (2019). Because the number of inseminations and health events were not consistently available for all herds over the entire time period, the final equation for calculating lifetime resilience scores (RS) excluded these variables and was as shown in Equation [1]:

$$
\begin{aligned}
& R S_{i}=\overline{C I}+300 \times L_{i}+\left(730-A F C_{i}\right)+\sum_{j=1}^{L_{i}-1}\left(\overline{C I}_{j}-C I_{i, j}\right) \\
& +\sum_{j=1}^{L_{i}}\left[\frac{\sum_{k=1}^{\max \left(305, D I M_{i, j}\right)} M Y_{i, j, k}}{\sum_{k=1}^{\max \left(305, D I M_{i, j}\right)} \frac{M Y_{i, j, k}}{M}}-1\right] \times 100 \\
& +\min \left[0,\left(\mathrm{DIM}_{i, L_{i}}-100\right)\right],
\end{aligned}
$$

where $R S_{i}=$ lifetime resilience score for cow $i ; \overline{C I}=$ average calving interval of the herd; $L_{i}=$ lactation number in which cow $i$ exited the herd (last lactation number of a cow); $A F C_{i}=$ age at first calving of cow $i$ (in d); $C I_{i, j}=$ calving interval of cow $i$ between the start of lactation $j$ and $(j+1) ; \overline{C I_{j}}=$ average calving interval between the start of lactation $j$ and $(j+1)$ of all cows in the herd; $M Y_{i, j, k}=$ milk production (in $\mathrm{kg}$ ) of cow $i$ at day $k$ of lactation $j ; \overline{M Y_{i, j, k}}=$ average milk production (in $\mathrm{kg}$ ) at day $k$ of all cows in the herd in lactation $j ; D I M_{i, j}=$ DIM of cow $i$ at the end of lactation $j$; and $D I M_{i, L_{i}}=$ DIM of cow $i$ at the end of her last lactation $L_{i}$.

Thus, each RS is composed of (1) a baseline equal to the average calving interval of that herd, to avoid negative lifetime resilience scores (this does not contribute to the ranking); (2) a bonus of 300 points given for each recalving (newly started lactation); (3) a penalty or bonus score given to cows respectively older or younger than 24 mo at their first calving, equal to 1 point per day longer or shorter than 730 d (i.e., 24 mo); (4) a penalty or bonus score equal to the number of days the calving interval is respectively shorter or longer than the average calving interval of the same parity in the herd; (5) a penalty or bonus score equal to the percent- age by which the 305-d milk production is respectively lower or higher than the average 305-d production of the corresponding parity for all lactations in the herd, reflecting production performance in the most relevant part of the lactation; and (6) a penalty score equal to $100-D I M_{e x i t}$ for cows exiting the herd before d 100 in lactation, assuming that these cows are involuntarily removed from the herd. The weights of the variables in Equation [1] were arbitrarily chosen using expert knowledge and ensured that the number of lactations started (i.e., $L_{i}$ in Eq. [1]) had the greatest effect on the RS. This way, cows with a high ability to recalve (thus, cows that stay in the herd for several lactations) had high resilience scores, whereas other variables gave only secondary corrections that allowed discrimination between all cows reaching a certain parity. The RS was used to rank the cows within farms, resulting in an on-farm lifetime resilience rank (RR) reflecting the lifetime resilience performance of each animal within the herd. Using this lifetime RR in the rest of the study permitted us to distinguish the least from the most resilient animals on a certain farm, without the exact weights or points assigned to each variable in Equation [1] having an important influence on the results. In the lifetime RR, high-ranked cows ("highly resilient animals") represent animals recalving many times, having the (theoretically) optimal age at first calving, having short calving intervals (and thus good reproductive performance), and producing proportionally more milk (i.e., taking lactation length into account) compared with their herdmates. The number of lactations affects this ranking the most, because of the 300 points added for each new lactation started. For example, if the average CI of a herd is $400 \mathrm{~d}$, the average CI between the start of first and second parity is $380 \mathrm{~d}$, and the average 305-d milk production in first lactation is 8,000 $\mathrm{kg}$. Consider a cow in this herd that calved twice, first at the age of $775 \mathrm{~d}$ and second after a 420-d calving interval, producing $5 \%$ more milk than herd average in the first $305 \mathrm{~d}$ of the first lactation and $20 \%$ less than her herd peers in the first $90 \mathrm{~d}$ of the second lactation. After being culled at d 90 in the second lactation, this cow would receive a lifetime resilience score of $\mathrm{RS}=$ $400+300 \times 2+(730-775)+(380-420)+5-20$ $+(90-100)=890$ points.

Before entering the lifetime RR in the models, it was scaled for each farm using $R R_{\text {scaled }}=\left(R R-R R_{\text {min }}\right) /$ $\left(R R_{\max }-R R_{\min }\right)$, with $R R_{\min }=1$, and $R R_{\max }=$ the maximum rank (equivalent to the number of cows included in the ranking for that farm). The resulting $R R_{\text {scaled }}$ varied between 0 (i.e., the highest-ranked cow) and 1 (i.e., the lowest-ranked cow), and, thus, no scale effects caused by the varying number of animals included per farm would influence the prediction models. 
In the rest of this manuscript, "RR" refers to the scaled RR.

\section{Sensor Features}

The time series data of 2 sensors were included in this study: (1) milk meter sensors from which daily milk yields were calculated and (2) activity sensors from which the 2-hourly raw data were aggregated into daily activity records. Sensor features were calculated for each of the cows for which the first lactation was longer than $200 \mathrm{~d}$, because $200 \mathrm{~d}$ is enough to grasp a good image of the time series dynamics, as the second part of the lactation curve after the peak can be estimated by a linear function (Wood, 1967). Only the data of the first $305 \mathrm{~d}$ of the first lactation were included for the calculations.

Milk Yield. As explained in greater detail in Appendix A, in total 30 milk yield sensor features (SF) were calculated based on the daily milk yield dynamics. Moreover, a methodology was developed to calculate $\mathrm{SF}$ from the dynamics of the lactation curves using both the theoretical shape and the deviations from this theoretical shape as proxies for the cow's physiological status. Accordingly, SF were defined in the following categories: (1) lactation shape characteristics, including peak yield, consistency, DIM of peak, and others; (2) goodness-of-fit and variability measures, including the characteristics of lactation model residuals; and (3) perturbation features characterizing the disturbances in the lactation dynamics and including the development and recovery rates, the number of perturbations, and so on. To determine the theoretical shape of the lactation curve (i.e., potential production when no perturbations are present), a simple lactation model was iteratively fitted such that perturbations were excluded and, thus, did not influence the lactation model's coefficients (Adriaens et al., 2018). The chosen model was the nonlinear Wood model: $T M Y=A \times e^{-B \times D I M} \times D I M^{C}$ with $A, B$, and $C$ being the model's coefficients, $T M Y$ the total daily milk yield in $\mathrm{kg}$, and $D I M$ the days in milk expressed in days (Wood, 1967). The Wood model (gamma function) describes the lactation curve with an increasing phase, a peak, and an almost linear decreasing phase, describing the overall lactation dynamics with only 3 coefficients. Its simplicity reduces the computational power needed when repeatedly fitting the nonlinear model, and therefore we preferred this equation over more complex lactation models. In each iteration, the residuals were calculated by subtracting the fitted Wood model from the milk yield data. Next, all the residuals smaller than $85 \%$ of the theoretical curve (i.e., Wood's model) were removed, and the model was refitted in a next iteration. This procedure was repeated for each lactation curve individually, until the difference of the average root mean squared error (RMSE) between 2 iterations was smaller than 0.10 $\mathrm{kg}$ for that curve, or for at most 20 iterations. The final model coefficients represent the lactation shape when no perturbations would have been present, and the model's residuals reflect the perturbations and "unexpected" milk yield dynamics. An example of the daily milk yield data, the iterated Wood model, and the corresponding residuals is shown in Figure 1.

Next, the milk yield SF were calculated from (a) the final coefficients of Wood's model $(A, B$, and $C)$, (b)

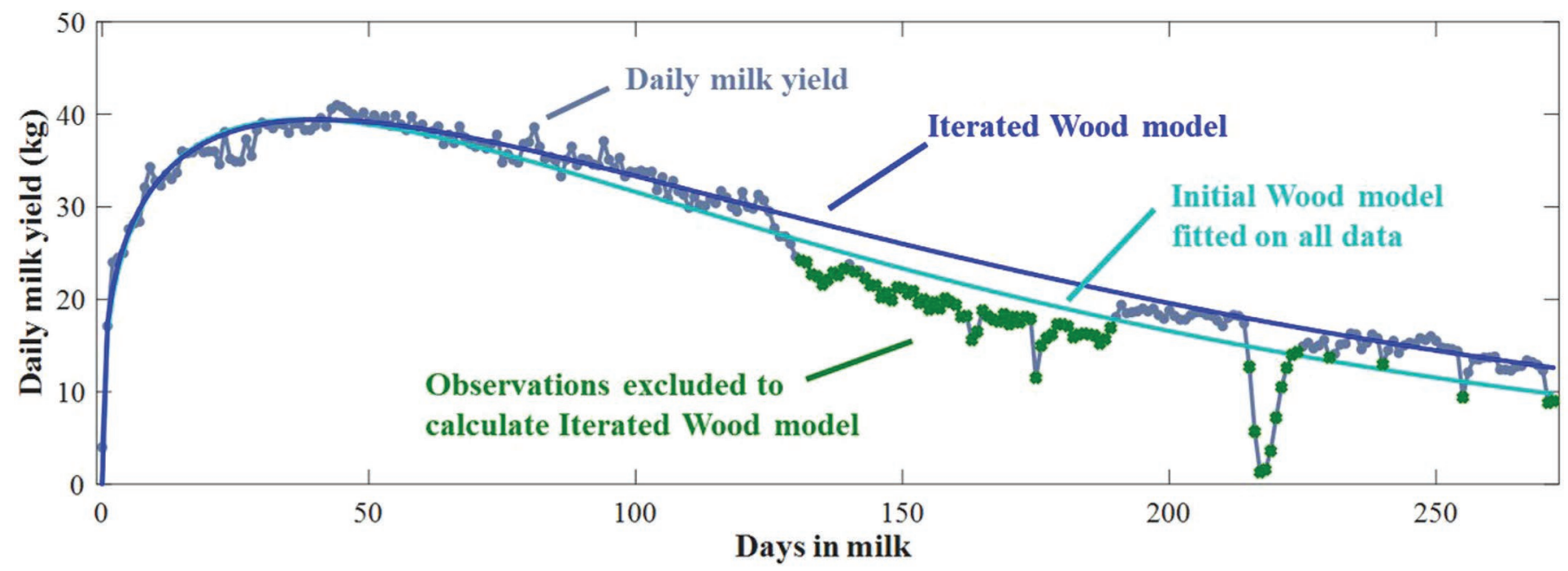

Figure 1. Example of a lactation curve with daily milk yields, the corresponding initial Wood model fitted on all daily milk yield data, and the final Wood model fitted iteratively by excluding daily milk yields lower than $85 \%$ of the estimated curve. The residuals of the latter curve are used to characterize perturbations (e.g., representing health events). 
the residuals of all daily milk yield records, and (c) the periods identified as perturbations. For the latter, major events (i.e., periods of at least $10 \mathrm{~d}$ of successively negative residuals with at least $1 \mathrm{~d}$ of milk production lower than $80 \%$ of the theoretical production) were discriminated from minor events (i.e., periods of at least 5 $\mathrm{d}$ of successively negative residuals with at least $1 \mathrm{~d}$ of milk production between $90 \%$ and $80 \%$ of the expected production). It was expected that large perturbations (major events) represent severe health problems, and smaller (minor) perturbations are probably linked to chronic or subclinical infections. Based on our expert knowledge, we assumed that these major or minor perturbations might affect culling and re-breeding decisions and, thus, resilience and longevity differently (Mulder and Rashidi, 2017). Therefore, they were entered in the models separately. A detailed description of the milk yield SF and how they were calculated can be found in Appendix A.

Activity. In addition to the lactation SF, for DS2 activity SF were also calculated from the daily aggregated raw activity measures. Fifteen different SF were defined in the following categories: (1) features related to the absolute (within-herd) levels (i.e., variability and autocorrelation); (2) fertility-related characteristics based on short spikes representing estrous behavior; and (3) overall activity-related characteristics based on changes in average activity during longer periods of time that possibly relate to, for instance, health events. To identify the short spikes of the second category, a median smoother using a window of $4 \mathrm{~d}$ was used and subtracted from the raw daily activity data to obtain residual activity levels. A short spike was identified as an increase above $40 \%$ of the maximal residual. For the identification of the longer-term patterns in the data, a 20-d window median smoother was applied and subtracted from the daily activity data to obtain the residuals. A threshold of $20 \%$ of these minimal and maximal activity residuals was set to identify changes in activity of several days compared with the previous period. The details for the activity SF calculations are given in Appendix B. Although all the raw values in DS2 had similar variability and magnitude (i.e., with 2-hourly measures between 0 and 300 and similar longitudinal patterns), the developed procedure can be applied on all sorts of activity data, including those originating from other types of sensors independently of the exact activity levels, as long as daily measurements are available. In that case, the decision criteria for detecting changes in the residuals might be reconsidered.

Standardization. The mean and SD differed across SF. For example, DIM of peak varied between 10 and $150 \mathrm{~d}$, whereas lactation persistency comprised values between 0.001 and 1 . When using the $\mathrm{SF}$ as variables in a prediction model, this can cause an imbalance in the fitting and selection procedure, and it limits the interpretation of the model regression coefficients. Therefore, standardization of the SF was needed. Before entering the SF in the models, each SF was standardized within herd using mean centering (i.e., subtracting the within-herd mean of that SF) and by dividing them by the within-herd SD. Accordingly, the standardized SF within a herd have a mean of 0 and an SD of 1 , which thus corrects for differences in their order of magnitude and solves interpretability issues. This standardization step ensures that a higher absolute value of a model coefficient indicates a larger effect on the model outcome (i.e., the lifetime RR). Standardized SF (both milk yield and activity) with values smaller than -3 or higher than 3 (mean $\pm 3 \times \mathrm{SD}$ ) were considered as outliers and replaced by 0 (i.e., the average value) to avoid missing and unbalanced data. The objective was to develop a tool to evaluate and forecast the (phenotypic) performance of an animal in the herd early in her productive life, to leave time to make breeding decisions that would directly contribute to the farm's performance, and so that "high-risk" animals can be monitored more closely. Therefore, in this study, only the first-parity SF were taken into account as proxies for performance, health, and fertility, to predict cows' lifetime resilience and recalving ability on farm.

\section{Exploratory Analysis}

In this study, a model was sought to predict the lifetime RR of all the animals on a specific farm. Ideally, a common model structure that is valid for all farms would be obtained, as this would allow the calculation of a limited and universal number of SF indicative of animals' lifetime resilience. As a first step to evaluate the consistency between the SF and the lifetime RR across farms, the Pearson linear correlation coefficient between each $\mathrm{SF}$ and the lifetime $\mathrm{RR}$ at individual farm level was calculated. High positive and negative correlations would indicate a strong effect of that SF on the lifetime RR, and thus a potential candidate for inclusion in further prediction models.

In a second step, mutual correlations between the SF were explored for all farms together. This initial data exploration, using data of all farms together, pointed out some significant (but small) linear correlations between the SF. However, at individual farm level, these correlations were often inconsistent, and the sign of the correlations differed between farms. To investigate whether an underlying latent structure existed in the $\mathrm{SF}$ and avoid future multicollinearity in the prediction 
models, a principal component analysis was carried out on the SF of both DS1 and DS2. These principal component analyses showed that respectively 8 and 24 principal components with eigenvalues higher than 1 (Kaiser criterion) explained only $71 \%$ and $74 \%$ of the variance, suggesting that a latent structure for data reduction over all farms did not exist.

\section{Individual Farm Model Development}

Several multivariate modeling techniques, including partial least squares and general linear mixed models, were tested, but all had poor prediction performance (with classification results equal to or worse than what random classification would have given; i.e., less than one-third correctly classified) or showed significant overfitting of the data. Ultimately, a separate multivariate linear regression model relating the $\mathrm{SF}$ to the lifetime RR within farm was constructed, as follows (Eq. [2]):

$$
R R_{\text {scaled }}=\boldsymbol{\beta} \mathbf{X}+\varepsilon,
$$

with $R R_{\text {scaled }}$ being the scaled lifetime $\mathrm{RR}$ between 0 and 1 , as defined above. The $\boldsymbol{\beta}$ vector contains the regression coefficients for the standardized SF in the design matrix $\mathbf{X}$, and $\varepsilon$ is the residual errors. A backward stepwise regression procedure was used to identify redundant $\mathrm{SF}$ in $\mathbf{X}$, applying a $P$-value of 0.2 as the inclusion threshold. This means that if there were a probability of more than $20 \%$ that removing the SF had a significant deteriorating effect on the prediction model, it was included. The chosen threshold might seem uncommonly high, but given the high variability in the SF both between and within farms, we deemed it relevant to include any feature having a tendency toward significance.

Ten-fold cross-validation (CV) was performed to evaluate the prediction performance of the obtained models and identify overfitting. To this end, 10 times all the cows of each farm were assigned to either the calibration set (90\% of the animals) or the validation set (10\% of the animals), using random sampling from a uniform distribution but applying the additional criterion that both the calibration and the validation set contained at least 1 animal ranked in the highest third, 1 in the middle third, and 1 in the lowest third of the ranked cows. In each $\mathrm{CV}$ cycle, the cows in the calibration set were used to estimate the regression coefficients $\beta$, and the obtained model was used to predict the $R R_{\text {scaled }}$ of the cows in the validation set. The average prediction results over all $10 \mathrm{CV}$ cycles were considered to represent the final model performance.

\section{Model Evaluation}

The initial model fit at farm level was evaluated using the RMSE (i.e., the RMSE $\mathrm{TR}_{\mathrm{R}}$, RMSE_training, calculated on the training set) and the adjusted $\mathrm{R}^{2}$, $R_{a d j}^{2}$, calculated as shown in Equation [3]:

$$
R_{a d j}^{2}=1-\frac{\left[1-\left(1-\frac{S S E}{S S T O}\right)\right](n-1)}{1-(k-1)},
$$

with $S S E$ the residual sum of squares of the regression, SSTO the total sum of squares (i.e., the mean value of the outcome $R R_{\text {scaled }}$ ), $n$ the number of data points of each farm, and $k$ the number of SF retained in the final model for that farm.

To evaluate classification performance and discriminate between high- and low-resilience cows (which is of practical relevance), the cows of each farm were divided into 3 different categories based on their ranking: high- $(\mathbf{H}$, top third), moderate- (M, middle third), and low- ( $\mathbf{L}$, bottom third) resilience animals. When the predicted $R R_{\text {scaled }}$ did not cover the full range of 0 to 1 , and to be able to calculate these high-, medium-, and low-ranked categories for each farm, a farm-individual correction factor (corr) was applied on the predicted $R R_{\text {scaled }}$ scores, as follows (Eq. [4]):

$$
\widehat{R R}_{\text {scaled,corr }, i}=\frac{\widehat{R R}_{\text {scaled }, i}-\mathrm{A}}{\mathrm{B}-\mathrm{A}},
$$

with $\widehat{R R}_{\text {scaled }, i}$ being the predicted $R R_{\text {scaled }}$ of the $i$ th cow and $A$ and $B$ farm-specific coefficients representing, respectively, the minimum and maximum of all the predicted $R R_{\text {scaled }}$ for that farm in the calibration set of each CV cycle. The $R R_{\text {scaled }}$ of the cows in the validation set of each CV cycle were predicted using each individual farm model (Eq. [2]), and their category $(\mathrm{H}$, $\mathrm{M}$, L) was determined after applying the correction using the farm-specific coefficients (Eq. [4]). Both the RMSE of cross-validation (RMSECV, Eq. [5]) and the classification accuracy were evaluated in this CV to assess the models' prediction performance:

$$
R M S E C V=\sqrt{\frac{1}{N} \sum_{1}^{N}\left(R R_{\text {scaled }, i}-\widehat{R R}_{\text {scaled }, i}\right)^{2}} .
$$

To evaluate whether a common model structure across farms could be identified or whether specific features are highly correlated with lifetime resilience in all 
farms, we evaluated the overlap in retained features for each farm, in terms of both their inclusion or exclusion in each farm-specific model and the sign of their regression coefficients.

Prediction performance improvement of the models, including and excluding activity features, was assessed using a one-sided paired $t$-test on the percentage correctly classified using the null hypothesis "activity features do not improve (i.e., increase) the percentage of correctly classified animals" and on the proportion oppositely classified using the null hypothesis "activity features do not improve (i.e., decrease) the percentage of oppositely classified animals."

\section{RESULTS AND DISCUSSION}

\section{Lifetime Resilience}

This study investigates the possibility of predicting "lifetime resilience" from SF of the first lactation. Currently, no consensus exists on what "resilience" exactly is, and definitions found in literature include the "ability to maintain performance regardless of pathogen burden" (Mulder and Rashidi, 2017) and "the adaptation ability to a broad range of environmental conditions" (König and May, 2018). Our approach differs from these definitions and considers lifetime resilience as the cumulative effect of good health and fertility, and a high adaptability to challenges, resulting in a long productive life span.

Figure 2 shows the lifetime resilience score plotted against the lactation in which the cows were culled, for one farm as an example. Each circle represents 1 animal on the farm, and a higher resilience score also means a higher lifetime resilience ranking. The animals on this example farm exited the farm between their first and seventh lactation. This figure confirms that, in general, for our definition of resilience, the total number of lactations each cow has started has the greatest influence on the final lifetime RR. The cows ranked lower than their herdmates with higher last lactation numbers are seen as spikes. These are mainly cows that are removed from the herd immediately after calving and, thus, for which the penalty given for exiting before d 100 in lactation has a large effect $\left(D I M_{i, L_{i}}\right.$ in Eq. [1]).

The inclusion of the 305-d yield originates from the idea that, to differentiate 2 animals exiting the herd after the same number of lactations, the one with the higher production in the first $305 \mathrm{~d}$ (thus, probably not having encountered severe health events) is probably the more resilient. Ideally, penalties or bonus points for health events and the number of inseminations would also be included, but health and insemination records were not sufficiently complete over the whole time period for all farms. Consistent and correct registration, collection, mining, and storage of data remains a challenge in the development of on-farm applications (Hudson et al., 2018).

\section{Sensor Feature Definition and Overview}

The present study shows an example of how realfarm high-frequency sensor data can be used beyond monitoring and detection applications (Boichard and Brochard, 2012). We used the longitudinal, high-granularity milk yield and activity data of respectively 27 and 13 commercial dairy operations with an AMS to calculate biologically meaningful features of the cows. This is a unique data set, not only because of its commercial nature (as opposed to research farm data) but also because these high-frequency time series allowed for the inclusion of the dynamics of milk yield and daily activity. The availability of at least 5 years of successive measurements per farm uniquely permitted us to study the accumulated effect of health and fertility traits of many animals over their entire lifetime.

Today, cows exit herds for many different reasons, of which the most common are poor reproduction per-

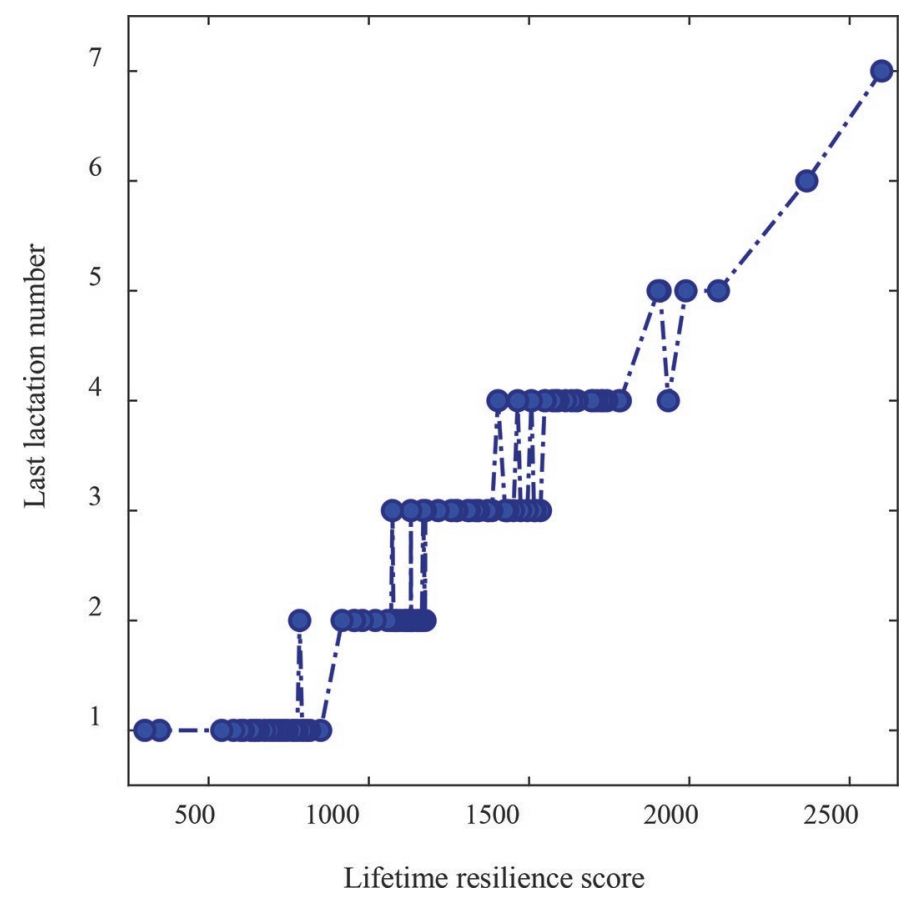

Figure 2. Example of the relation between the lifetime resilience scores of all the animals on an example farm (110 cows) against the parity number in which each animal exits the herd. Higher resilience scores generally correspond to higher final lactation numbers. 
Table 2. Overview of a selection of lactation and activity sensor features calculated on first-parity data for data set 1 (DS1) and data set 2 (DS2); detailed overviews of all the included features are given in Appendices A and B

\begin{tabular}{|c|c|c|}
\hline Item & $\begin{array}{c}\text { DS1 } \\
\text { Average } \pm \text { SD [range] }\end{array}$ & $\begin{array}{c}\text { DS2 } \\
\text { Average } \pm \text { SD [range] }\end{array}$ \\
\hline $\begin{array}{l}\text { No. of cows included } \\
\text { Theoretical 305-d yield } \\
\text { RMSE }^{1}(\mathrm{~kg} / \mathrm{d}) \\
\text { Peak yield }(\mathrm{kg}) \\
\text { DIM of peak lactation }(\mathrm{d}) \\
\text { Rate increasing part of the lactation curve }(\mathrm{kg} / \mathrm{d}) \\
\text { Persistency of the lactation curve }(\mathrm{kg} / \mathrm{d}) \\
\text { No. of perturbations per lactation } \\
\text { Losses in perturbations per lactation }(\mathrm{kg}) \\
\text { Activity skewness } \\
\text { No. of sharp and short activity peaks } \\
\text { DIM of first activity peak }(\mathrm{d}) \\
\text { No. of general activity changes }\end{array}$ & $\begin{aligned} 3,754 & \\
8,261 & \pm 1,772[2,688-13,755] \\
3.4 & \pm 1.4[1-28] \\
34 & \pm 6[15-61] \\
59 & \pm 25[1-248] \\
0.64 & \pm 0.28[0.08-6.7] \\
-0.05 & \pm 0.03[-0.15-0.12] \\
6.0 & \pm 3.1[0-17] \\
148 & \pm 124[0-1137]\end{aligned}$ & $\begin{aligned} 2,075 & \\
8,317 & \pm 1,874[2,689-13,755 \\
3.8 & \pm 1.5[1.2-28] \\
34 & \pm 6[14-61] \\
63 & \pm 27[1-207] \\
0.62 & \pm 0.31[0.08-6.7] \\
-0.04 & \pm 0.03[-0.15-0.12] \\
6.3 & \pm 3.2[0-17] \\
154 & \pm 132[0-1,129] \\
-0.05 & \pm 1.64[-5.19-8.77] \\
3.9 & \pm 2.7[0-18] \\
56 & \pm 64[1-305] \\
24 & \pm 16[2-94]\end{aligned}$ \\
\hline
\end{tabular}

${ }^{1} \mathrm{RMSE}=$ root mean squared error of the Wood model fitted on each lactation curve.

formance, udder health problems, metabolic disorders in early lactation, and claw health and locomotion disorders (Ahlman et al., 2011; Santos et al., 2016). The SF were calculated starting with expert knowledge and biological hypotheses on the supposed effects of these culling reasons on the sensor time series, and included features characterizing the perturbations and dynamics of the lactation and activity curves. For example, Elgersma et al. (2018) showed that fluctuations in milk yield can reflect the cow's health status. Table 2 gives a summary of the most important SF over all farms for DS1 and DS2. As can be seen from the minimum and maximum value of each SF, some of these SF have extreme values, which, upon further investigation, appear to result from erroneous calculations rather than from real deviating curves. These outliers were set to 0 for the analysis.

Both milk yield and activity features were defined using biological knowledge of how these time series typically respond to changes in health and nutritional status (Højsgaard and Friggens, 2010; Codrea et al., 2011; Bjerre-Harpøth et al., 2012). We therefore always started from the data-own baseline, which was identified using a median smoother that is insensitive to sudden changes or differences in absolute value or baselines. Through characterization of the residuals from this median smoother, and the correction and standardization at herd level, we were able to correct for group changes and differences in the intensity of the responses between herds.

\section{Predicting Lifetime Resilience Ranking from Milk Yield Features}

Pearson Linear Correlations. The Pearson linear correlation coefficients between the lactation SF and $\mathrm{RR}$ are shown in Figure 3. A high (positive or negative) correlation between an $\mathrm{SF}$ and the RR suggests a large effect of the SF on the RR. The average correlations $(\rho)$ per SF over all farms varied between $\rho=-0.134$ and $\rho$ $=0.1492$, and for some of the farms individual features showed correlations of more than \pm 0.4 . Visual exploration of the correlation scatter plots (results not shown) did not show nonlinear relationships either. Although consistency would have been expected, Figure 3 already suggests only little consistency across farms in which $\mathrm{SF}$ can be predictive for the lifetime RR of the cows of a particular farm. For example, some of the features represent the effect of health events on the milk yield data through the characterization of perturbations. Because we can imagine that severe health events and the associated losses negatively affect longevity on all the farms, we supposed that a consistently high correlation would exist between perturbation-related SF and RR. However, this consistency is lacking, especially in terms of the correlations' sign (negative vs. positive). The highest and most consistent correlations are obtained for SF representing model fit and size of the residuals [RMSE of the Wood model (SF2), number of residuals below $85 \%$ of the predicted value (SF23), and average size of the 3 largest negative residuals (SF24)].

Model Calibration. In the stepwise procedure for selecting the SF that are included in the multilinear regression model, the best possible combination of $\mathrm{SF}$ to fit the RR on each farm is determined, and SF are included or excluded depending on whether they improve the model fit. The CV step reveals whether the final model structure overfitted the training data and whether the selected SF are indeed meaningful for predicting the RR. If an SF is included in the multilinear regression model, the absolute value of its regression coefficient is directly related to its effect because of the standardization procedure of the SF (mean centering and equalizing the variance). 


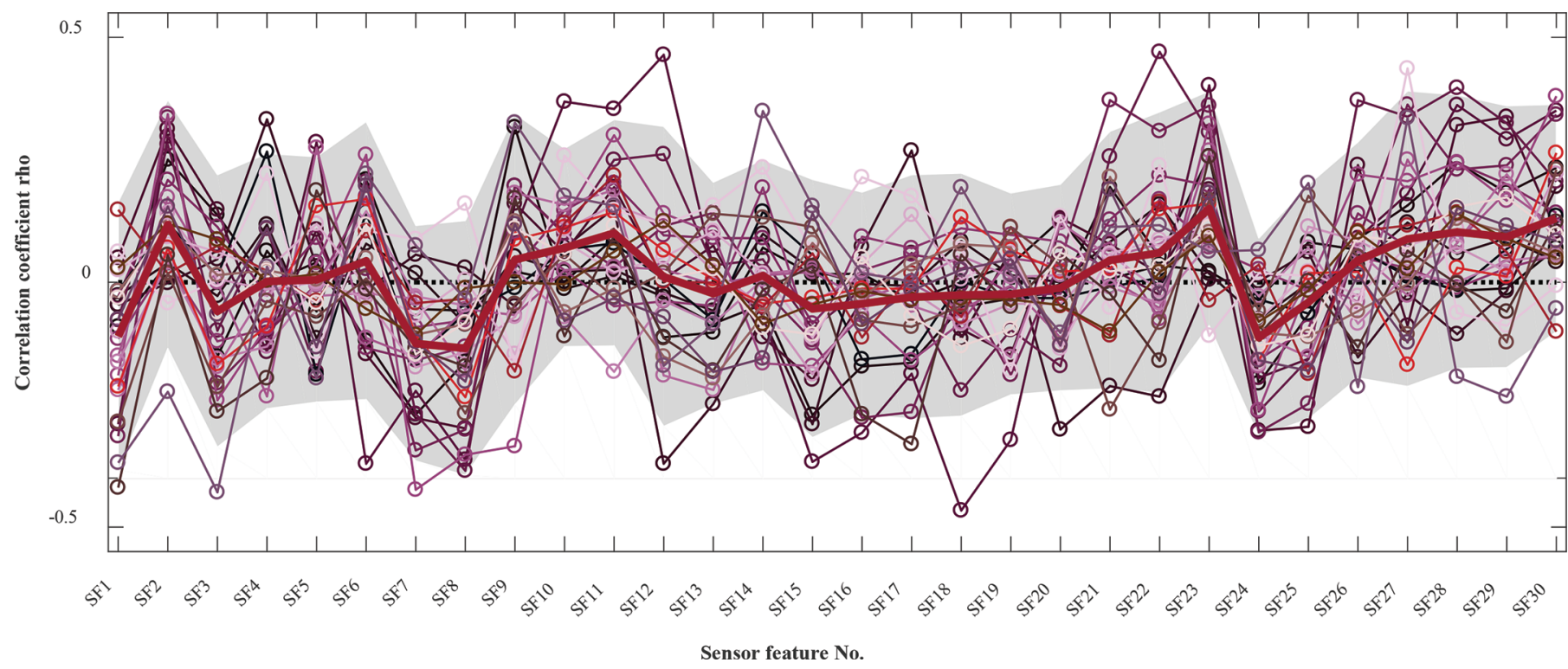

Figure 3. Pearson linear correlation coefficients between the lifetime resilience rank at farm level and the 30 lactation sensor features (SF) calculated on first-parity data. Each individual thin line represents the correlations for a particular farm $(\mathrm{n}=27)$. The shading represents the 95\% CI of the correlation coefficients $(\rho)$ over all farms. The details of SF are described in Appendix A. The lack of consistency in the correlations' signs and the magnitude demonstrate the large variability in the relation between the lifetime resilience and the lactation SF.

The $R_{a d j}^{2}$ of the individual multivariate linear regression models of each farm varied between 0.03 and 0.61 $(0.22 \pm 0.16$, mean $\pm \mathrm{SD})$ and the RMSE $\mathrm{TR}_{\mathrm{TR}}$ was between 0.17 and $0.27(0.23 \pm 0.03$, mean $\pm \mathrm{SD})$. Between 2 and 12 milk yield features were retained, and all SF were included at least once in one of the models of the individual farms (Table 3). The SF most often retained in the models were associated with the goodness of fit of the estimated Wood curves (SF21, 22, 25, 27, 28, 29), the size and number of perturbations (SF13, 14, 15), and their associated milk losses (SF11, 12, 18). This suggests that the SF that are proxies for subclinical or chronic health events are most informative over the $\mathrm{RR}$, and, thus, these health events influence the cow's longevity. It appears that farmers do take the health of the cows into account when making culling and reinsemination decisions, although not consistently and not on all farms. Moreover, the effects found in this study are rather weak, and in some cases, it can be assumed that only the combined result of different features or only the extreme values might influence productive life span and RR. For example, a cow with severe clinical mastitis is likely to show a large and sudden drop in milk yield (Rajala-Schultz et al., 1999; Gröhn et al., 2004; Andersen et al., 2011), whereas a cow with subclinical mastitis may have a lactation curve that can be well modeled with a lactation model and that appears to be normal. Both can influence reproduction performance and the probability of culling (Lavon et al.,
2010; Wathes, 2012; Wolfenson et al., 2015), but mathematically capturing the differences without additional health or treatment information is not possible. General lactation curve characteristics, such as peak height and peak DIM, slopes, rate of the increasing phase of the lactation, and persistency of the lactation after the peak, were included in the models of only 12 out of 27 farms, suggesting that, for example, having a high milk production in the first lactation compared with herdmates barely affects the RR (and thus the ability to recalve and longevity). The variability between farms is demonstrated again by the fact that the regression coefficients were consistently above or below 0 for only two out of the $30 \mathrm{SF}$, and so only two SF had a consistently positive or negative effect on the RR.

Cross-Validation. With the CV, the repeatability, generality, and overfitting of the models was tested. Within-farm CV showed similar performances (RMSEC $=0.24 \pm 0.03)$ compared with the $\mathrm{RMSE}_{\mathrm{TR}}$ of the initial models with all animals included, indicating that models were not overfitted. On average $46.7 \pm$ $8.0 \%$ of the animals were classified in the correct $\mathrm{H}, \mathrm{M}$, or L category, and on average $4.4 \pm 3.5 \%$ of the cows were classified high when they should have been low or vice versa. Also here the large differences in model performance between the different farms stands out, with a range of correctly classified cows between 35.8 and $70.0 \%$ and the range of oppositely classified cows between 0.0 and $16.5 \%$. When looking more deeply into which cows are predicted in the correct category, it was 
Adriaens et al.: PREDICTION OF RESILIENCE USING SENSOR DATA

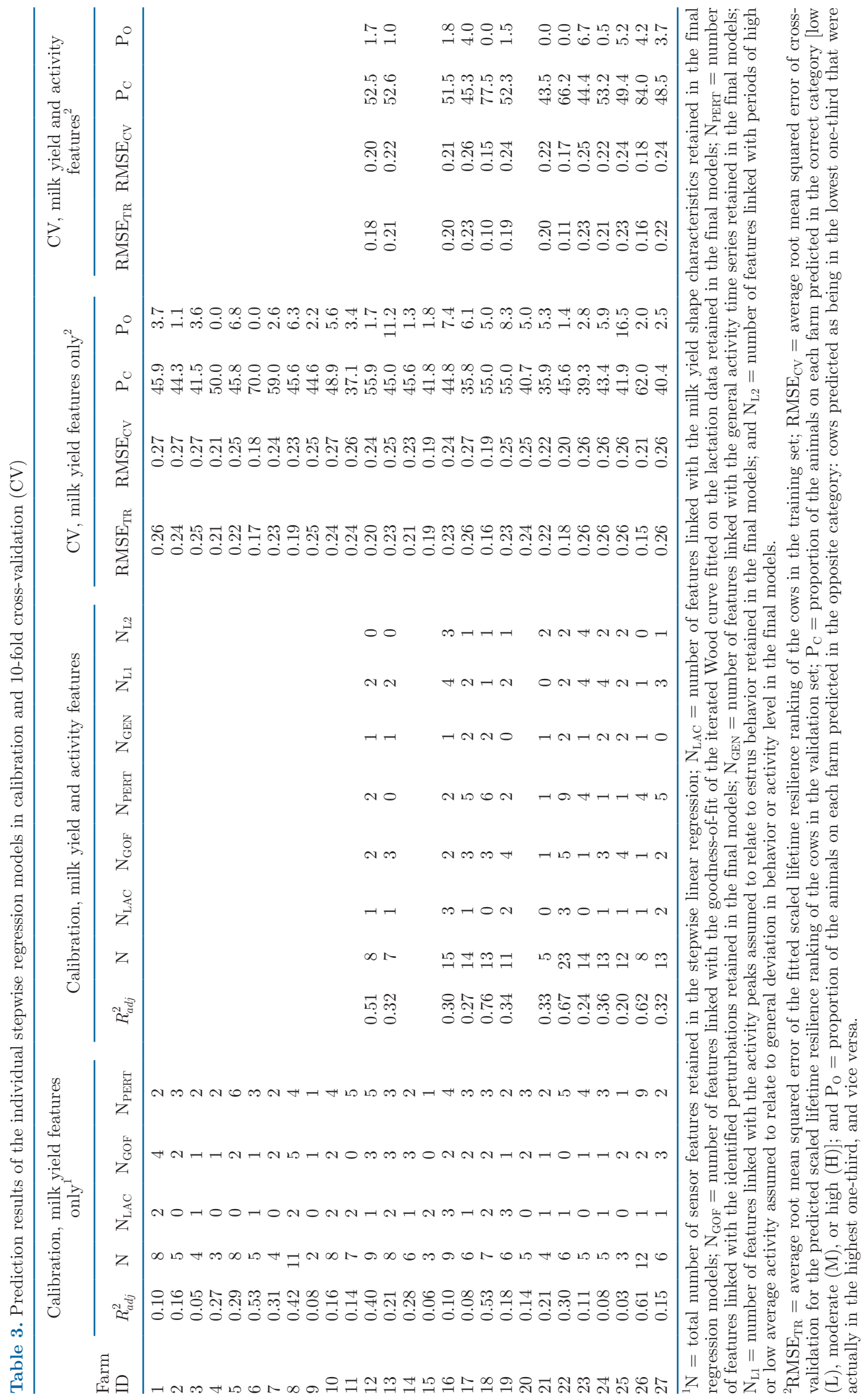




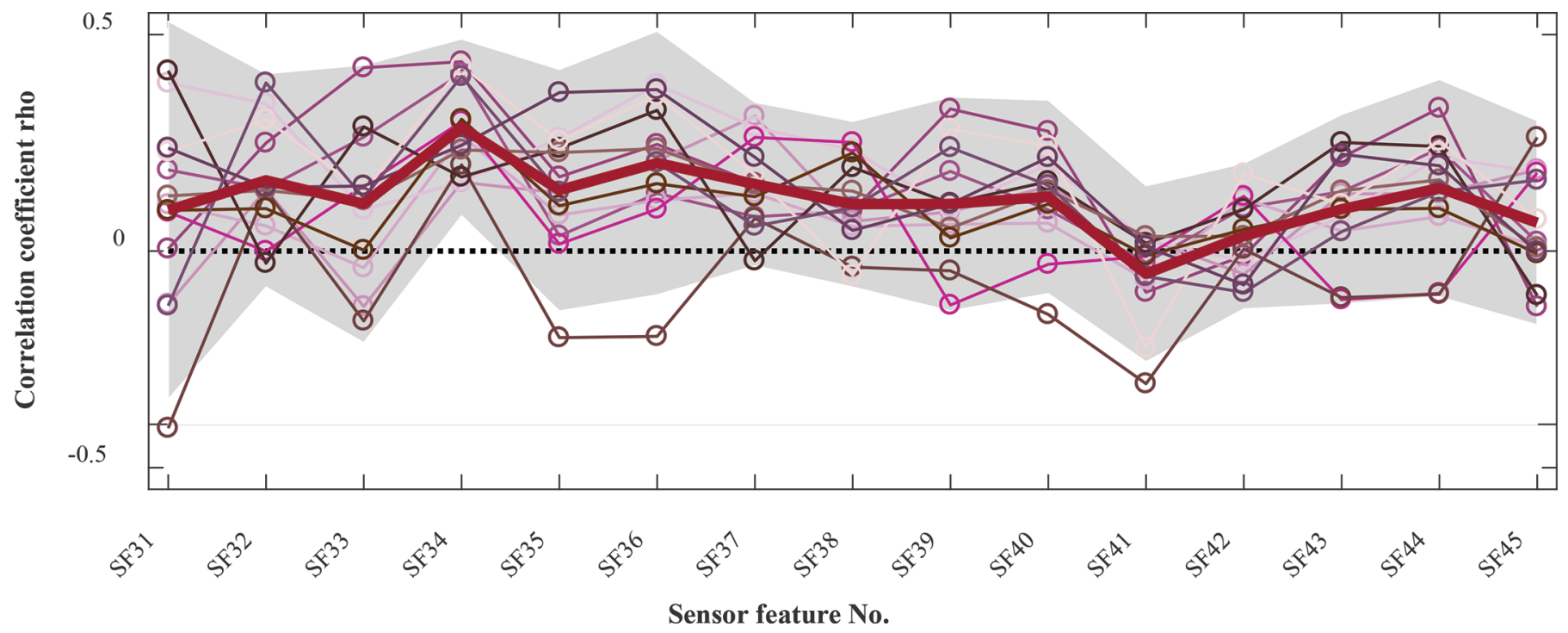

Figure 4. Pearson linear correlation coefficients between the lifetime resilience rank at farm level and the 15 activity sensor features (SF) calculated on first-parity data. Each individual thin line represents the correlations of a particular farm $(\mathrm{n}=13)$. The shading represents the 95\% CI of the correlation coefficients $(\rho)$ over all farms. The details of the activity SF are described in Appendix B. The lack of consistency in the signs and magnitudes of correlations demonstrates the large variability in the relation between the lifetime resilience and the activity SF. Only SF34 (number of sharp activity peaks corresponding to estrus) have a consistently positive correlation with the lifetime resilience rank.

found that the models do not correctly predict only animals exiting the herd after the first lactation but also cows exiting the herd in a later lactation. For cows culled already in the first lactation, health issues are expected to be the major reason (Pinedo et al., 2010). For cows culled at a later stage, it might not be expected that first-lactation features are predictive for the RR unless these characteristics are highly repeatable over time or represent chronic or repeating conditions that fail to cure. However, information on the exact reason and timing of culling of the cows could not be taken into account in the model, as this information was not available in the data sets. Because it is expected that this information can contribute to the model, future research should focus on solving this multidimensionality issue and developing new ways to take these complex interactions into account.

\section{Predicting Lifetime Resilience Ranking from Both Yield and Activity Features}

Pearson Linear Correlations. Data set 2 consisted of 13 farms for which, besides milk yield features (n $=30$ features $)$, activity features $(\mathrm{n}=15$ features $)$ could also be calculated. These features included both general characteristics of daily activity (skewness, variability, absolute daily level) and specific features associated with short-term and longer-period activity changes. Farm-individual Pearson correlation coefficients (Figure 4) between the activity features and the RR varied between $\rho=-0.41$ and $\rho=0.44$, and only the number of short activity peaks in SF34 was consistently associated with a higher ranking [lower number of peaks is associated with a higher resilience, $\rho=0.29 \pm 0.10$ (range: 0.16 to 0.44 )]. Several other activity features also had correlations nearly consistently above or below 0 , but these correlations stayed relatively low on average.

Model Calibration. The stepwise linear regression models included 6 to $24 \mathrm{SF}$ (both activity and milk yield features) and had $R_{a d j}^{2}$ values between 0.2 and 0.76 and $\mathrm{RMSE}_{\mathrm{TR}}$ values between 0.128 and 0.24 . The number of activity features retained in the final models was between 2 and 10, so the activity sensors seemed to be of added value for all of the farms in predicting their RR. Including activity features gave a higher $R_{a d j}^{2}$ and a lower RMSE $E_{T R}$ in the calibration, whereas the number of features retained was sometimes higher and sometimes lower. Again, very little consistency existed over the different farms in which features were included in the final models. None of the SF were kept in the models of all farms. The number of activity peaks and DIM of the first peak were retained most often (respectively 8 and 11 out of 13 times) and with a consistently positive regression coefficient (respectively 0.036 to 0.122 and 0.042 to 0.134$)$. Three of the SF $(6.6 \%)$ were never retained in any of the individual farm models.

Cross-Validation. The CV, using the same CV sets for these farms as in DS1 (i.e., the same animals were 
included in each set), showed reasonable performance, with an RMSECV of $0.22 \pm 0.03$ (range 0.15 to 0.26 ). On average $55.5 \pm 12.1 \%$ (range 43.5 to $84.0 \%$ ) of cows were predicted in the correct category $(\mathrm{H}, \mathrm{M}$, or $\mathrm{L})$, and $2.3 \pm 2.1 \%$ (range 0.0 to $6.7 \%$ ) of them were predicted high where they were actually low, or vice versa. This means that, from the wrongly classified animals, respectively $91.8 \%$ and $94.1 \%$ were predicted in an adjacent category. Over all the farms, including activity features improved the correct classification with $9.3 \pm$ $7.9 \%(P<0.01)$. The classification worsened in only 2 farms compared with when only milk yield features were included. The proportion classified in the opposite category decreased with on average $3.5 \pm 4.5 \%$, ranging from 5.9 to $2.3 \%$ (significant difference, $P<0.01$ ).

Despite the variability between and within farms and the fact that we could not find SF that were commonly informative to predict RR over all farms, the prediction and classification performance of the individual farm models was in many cases significantly higher than the product of a random classification (i.e., one-third correctly classified). Furthermore, including the activity features demonstrated a significant added value compared with using the daily milk yield features alone $(P$ $<0.01$ ). A correct classification of up to $84 \%$ of the animals suggests that at least part of the variability in the RR is correctly captured by the SF.

One way to explain the lack of a common model structure and the observed differences in prediction performance is the variability in culling, reproduction, and health management between farms and even within farms. For example, management practices might have differed over the considered time span because of changing motivations and preferences of the farm staff, economic context, animals' genotypes and phenotypes, farm facilities, feed, and more. Besides the time-varying component, the following factors can also explain part of the limited prediction performance on some farms: (1) for this study, only features of the first lactation were included, to ensure applicability of the model for decision support; (2) the lifetime resilience ranking is based on the limited data available in the commercial situation and was defined by experts; (3) a large difference exists in the number of animals included per farm, possibly affecting the results.

\section{Model Use and Implications}

Predicting Lifetime Resilience Ranking Supports Breeding and Culling Decisions. Reliable prediction of lifetime resilience within a farm would allow for a more consistent approach to the management actions concerning advanced breeding (e.g., sexed se- men, embryo transfer, ovum pick-up, use of beef semen, or selection of animals not to breed the replacement heifers from) or culling decisions after the first lactation (Mapletoft and Hasler, 2002; Vandeweerd et al., 2012; Boichard et al., 2015). In this way, breeding decisions for cows in the second parity and higher could be made using both the genetic or genomic (available once the animal is born) and the phenotypic sensor-derived information (once an animal has completed her first lactation). The latter would provide information on how well the animal performs in her specific farm environment, which optimizes sustainable productivity from the available animals on farm. In practice, discrimination between cows with high and low lifetime resilience would benefit a farmer even when the exact rankings remain unknown, because the farmer's decision would not generally be different for, for example, the fifth or the tenth ranked cow in the herd. Moreover, prediction of lifetime resilience also allows for the identification of animals with a low expected RR. These cows can be targeted for more detailed monitoring in higher lactations. In practice, the resilience ranking offers a transformative opportunity to evaluate herd health performance based on automated data collection and analysis. This analysis can be presented to the herd advisor or veterinarian during, for instance, regular herd health visits. The cows in the herd that are expected to have a low resilience based on this analysis can be submitted to preventive checkups, and upon detection of a problem (e.g., reproduction or health issues), targeted management actions can be undertaken (e.g., more frequent milking, milking these cows separately, putting them in a different production group, submitting them to adapted reproduction protocols).

This study also advocates for evidence-based decision making on modern dairy farms, supporting more economically sound and sustainable management actions. Despite the high prediction performance on some of the farms, the lack of a common model structure and the low performance on other farms suggest that further data-based rationalization of decisions is needed. To do so, dedicated data processing, in which the biology of the cows within their farm contexts is taken into account, is essential, and ideally other key farm context indicators should also be included in the resulting tools (e.g., herd demographics, robot or parlor capacity, economic environment).

Model Use Beyond Decision Support. With the collection and re-evaluation of this sensor-based information over many years, general phenotypic information on complex traits for future breeding goals is also collected at herd level. From this, sires that perform well under many different environmental conditions can 
be identified. In this way, the proposed tool can be used in the context of precision phenotyping of traits that are the combined results of physiological well-being and performance, and future genetic selection based on these new traits becomes possible.

\section{CONCLUSIONS}

In this study, we demonstrated that resilience ranking and productive life span of modern dairy cows on AMS farms in Belgium and the UK could be predicted using farm-individual models based on first-lactation sensor data. With the milk yield and activity SF selected at farm level, we reached classification performances (low, moderate, or high resilience) of up to $84 \%$, and only $2.3 \pm 2.1 \%$ (mean $\pm \mathrm{SD}$ ) of cows were predicted in the opposite category. This shows the potential of high-frequency milk yield and activity sensor data to rationalize evidence-based breeding and culling decisions. However, a common model structure across all farms could not be found, which shows the variability between farms and highlights the need for biologically sound and context-dependent data processing tools. Once a lifetime resilience-predicting tool is established, the farmer and the livestock sector could benefit from it not only for management and decision support but also at genetic level in the context of new precision phenotyping proxies for complex traits.

\section{ACKNOWLEDGMENTS}

Ines Adriaens received funding from the Research Foundation Flanders (Brussels, Belgium) through grants No. 11ZG916N and V423719N and from a Katholieke Universiteit Leuven (Belgium) postdoctoral mandate grant No. PDM/19/132. The data from this study were collected in the format of farm software back-up files by the authors, and the resulting database used is owned by the authors. Part of the data were collected in the context of the VLAIO LA-trajectory "MastiMan," grant No. HBC.2016.0774 by Igor Van den Brulle and Sofie Piepers from the University of Ghent, Flanders (Belgium; Department of Reproduction, Obstetrics and Herd Health, M-Team Mastitis and Milk Quality Research Unit). This work is part of the GenTORE project that has received funding from the European Union's Horizon 2020 research and innovation program (Paris, France), under grant agreement No. 727213. Katherine Lumb (RAFT Solutions Ltd., Ripon, UK) also contributed to the data collection. We thank Carmen Adriaens (Bernstein Laboratory, MGH, Boston, MA) for her critical reading of the manuscript. The authors have not stated any conflicts of interest.

\section{REFERENCES}

Adriaens, I., T. Huybrechts, B. Aernouts, K. Geerinckx, S. Piepers, B. De Ketelaere, and W. Saeys. 2018. Method for the short-term prediction of milk yield at the quarter level to improve udder health monitoring. J. Dairy Sci. 101:10327-10336. https://doi.org/10 $.3168 /$ jds.2018-14696.

Ahlman, T., B. Berglund, L. Rydhmer, and E. Strandberg. 2011. Culling reasons in organic and conventional dairy herds and genotype by environment interaction for longevity. J. Dairy Sci. 94:15681575. https://doi.org/10.3168/jds.2010-3483.

Andersen, F., O. Østerås, O. Reksen, and Y. T. Gröhn. 2011. Mastitis and the shape of the lactation curve in Norwegian dairy cows. J. Dairy Res. 78:23-31. https://doi.org/10.1017/S0022029910000749.

Ben Abdelkrim, A., L. Puillet, P. Gomes, and O. Martin. 2019. Lactation curve model with explicit representation of perturbations as a phenotyping tool for dairy livestock precision farming. PCI Animal Science https://doi.org/10.1101/661249.

Bjerre-Harpøth, V., N. C. Friggens, V. M. Thorup, T. Larsen, B. M. Damgaard, K. L. Ingvartsen, and K. M. Moyes. 2012. Metabolic and production profiles of dairy cows in response to decreased nutrient density to increase physiological imbalance at different stages of lactation. J. Dairy Sci. 95:2362-2380. https://doi.org/10 $.3168 /$ jds.2011-4419.

Boichard, D., and M. Brochard. 2012. New phenotypes for new breeding goals in dairy cattle. Animal 6:544-550. https://doi.org/10 $.1017 /$ S1751731112000018.

Boichard, D., V. Ducrocq, and S. Fritz. 2015. Sustainable dairy cattle selection in the genomic era. J. Anim. Breed. Genet. 132:135-143. https://doi.org/10.1111/jbg.12150.

Cabrera, V. E. 2018. Invited review: Helping dairy farmers to improve economic performance utilizing data-driving decision support tools. Animal 12:134-144. https://doi.org/10.1017/S1751731117001665.

Codrea, M. C., S. Højsgaard, and N. C. Friggens. 2011. Differential smoothing of time-series measurements to identify disturbances in performance and quantify animal response characteristics: An example using milk yield profiles in dairy cows. J. Anim. Sci. 89:3089-3098. https://doi.org/10.2527/jas.2010-3753.

de Jong, A., F. El Garch, S. Simjee, H. Moyaert, M. Rose, M. Youala, and E. Siegwart. 2018. Monitoring of antimicrobial susceptibility of udder pathogens recovered from cases of clinical mastitis in dairy cows across Europe: VetPath results. Vet. Microbiol. 213:7381. https://doi.org/10.1016/j.vetmic.2017.11.021.

Elgersma, G. G., G. de Jong, R. van der Linde, and H. A. Mulder. 2018. Fluctuations in milk yield are heritable and can be used as a resilience indicator to breed healthy cows. J. Dairy Sci. 101:12401250. https://doi.org/10.3168/jds.2017-13270.

Friggens, N. C., and Y. De Haas. 2019. Resilience: Reference measures based on longer-term consequences are needed to unlock the potential of precision livestock farming technologies for quantifying this trait. Accessed Jun. 15, 2019. https://www.gentore.eu/ uploads/1/0/7/4/107437499/gentore_working_doc_resilience_22 .01 .2019 .pdf.

Friggens, N. C., and V. M. Thorup. 2015. From monitoring to precision phenotyping: Towards a systemic use of precision livestock measures in dairy herds. Proc. N.Z. Soc. Anim. Prod. 15:146-148.

Gröhn, Y. T., D. J. Wilson, R. N. González, J. A. Hertl, H. Schulte, G. Bennett, and Y. H. Schukken. 2004. Effect of pathogen-specific clinical mastitis on milk yield in dairy cows. J. Dairy Sci. 87:33583374. https://doi.org/10.3168/jds.S0022-0302(04)73472-4.

Højsgaard, S., and N. C. Friggens. 2010. Quantifying degree of mastitis from common trends in a panel of indicators for mastitis in dairy cows. J. Dairy Sci. 93:582-592. https://doi.org/10.3168/jds.2009 -2445 .

Hudson, C., J. Kaler, and P. Down. 2018. Using big data in cattle practice. In Pract. 40:396-410. https://doi.org/10.1136/inp.k4328.

König, S., and K. May. 2019. Invited review: Phenotyping strategies and quantitative-genetic background of resistance, tolerance and resilience associated traits in dairy cattle. Animal 13:897-908. https://doi.org/10.1017/S1751731118003208. 
Lavon, Y., G. Leitner, H. Voet, and D. Wolfenson. 2010. Naturally occurring mastitis effects on timing of ovulation, steroid and gonadotrophic hormone concentrations, and follicular and luteal growth in cows. J. Dairy Sci. 93:911-921. https://doi.org/10.3168/ jds.2009-2112.

Mapletoft, R., and J. Hasler. 2002. Assisted reproductive technologies in cattle: A review. Sci. Tech. Rev. Off. Int. des Epizoot. 24:393403. https://doi.org/10.1057/palgrave.development.1100303.

Mulder, H. A., and H. Rashidi. 2017. Selection on resilience improves disease resistance and tolerance to infections. J. Anim. Sci. 95:3346-3358. https://doi.org/10.2527/jas2017.1479.

Pinedo, P. J., A. De Vries, and D. W. Webb. 2010. Dynamics of culling risk with disposal codes reported by Dairy Herd Improvement dairy herds. J. Dairy Sci. 93:2250-2261. https://doi.org/10.3168/ jds.2009-2572.

Rajala-Schultz, P. J., Y. T. Gröhn, C. E. McCulloch, and C. L. Guard. 1999. Effects of clinical mastitis on milk yield in dairy cows. J. Dairy Sci. 82:1213-1220. https://doi.org/10.3168/jds.S0022 -0302(99)75344-0.

Royal, M. D., A. O. R. Darwash, A. P. F. F. Flint, R. Webb, J. A. Woolliams, and G. E. Lamming. 2000. Declining fertility in dairy cattle: Changes in traditional and endocrine parameters of fertility. Anim. Sci. 70:487-501. https://doi.org/10.1017/S1357729800051845.

Rutten, C. J., A. G. J. Velthuis, W. Steeneveld, and H. Hogeveen. 2013. Invited review: Sensors to support health management on dairy farms. J. Dairy Sci. 96:1928-1952. https://doi.org/10.3168/ jds.2012-6107.

Santos, J. E. P., R. S. Bisinotto, and E. S. Ribeiro. 2016. Mechanisms underlying reduced fertility in anovular dairy cows. Theriogenology 86:254-262. https://doi.org/10.1016/j.theriogenology.2016.04 .038 .

Sorg, D., M. Wensch-Dorendorf, K. Schöpke, G. Martin, R. Schafberg, N. Reinhold, S. Pache, and H. Swalve. 2017. Genetic analysis of new progesterone-based fertility traits in dairy cows measured on-farm. J. Dairy Sci. 100:8205-8219. https://doi.org/10.3168/jds .2016-11865.

Steeneveld, W., and H. Hogeveen. 2015. Characterization of Dutch dairy farms using sensor systems for cow management. J. Dairy Sci. 98:709-717. https://doi.org/10.3168/jds.2014-8595.

Tenghe, A. M. M., A. C. Bouwman, B. Berglund, E. Strandberg, J. Y. Blom, and R. F. Veerkamp. 2015. Estimating genetic parameters for fertility in dairy cows from in-line milk progesterone profiles. J. Dairy Sci. 98:5763-5773. https://doi.org/10.3168/jds.2014-8732.

van Knegsel, A. T. M., H. M. Hammon, U. Bernabucci, G. Bertoni, R. M. Bruckmaier, R. M. A. Goselink, J. J. Gross, B. Kuhla, C. C. Metges, H. K. Parmentier, E. Trevisi, A. Tröscher, and A. M. van Vuuren. 2014. Metabolic adaptation during early lactation: Key to cow health, longevity and a sustainable dairy production chain. Perspect. Agric. Vet. Sci. Nutr. Nat. Resour. 9:1-15. https://doi .org/10.1079/PAVSNNR20149002.

Vandeweerd, J. M., N. Kirschvink, P. Clegg, S. Vandenput, P. Gustin, and C. Saegerman. 2012. Is evidence-based medicine so evident in veterinary research and practice? History, obstacles and perspectives. Vet. J. 191:28-34. https://doi.org/10.1016/j.tvjl.2011.04 .013 .

Wathes, D. C. 2012. Mechanisms linking metabolic status and disease with reproductive outcome in the dairy cow. Reprod. Domest. Anim. 47:304-312. https://doi.org/10.1111/j.1439-0531.2012 .02090.x.
Wolfenson, D., G. Leitner, and Y. Lavon. 2015. The disruptive effects of mastitis on reproduction and fertility in dairy cows. Ital. J. Anim. Sci. 14:4125. https://doi.org/10.4081/ijas.2015.4125.

Wood, P. 1967. Algebraic model of the lactation curve in cattle. Nature 216:164-165. https://doi.org/10.1038/216164a0.

\section{ORCIDS}

I. Adriaens $\odot$ https://orcid.org/0000-0001-9768-2308

W. Ouweltjes @ https://orcid.org/0000-0001-5455-0110

B. Aernouts (ㄴ) https://orcid.org/0000-0001-6266-3019

J. Statham (1) https://orcid.org/0000-0002-2808-8660

\section{APPENDICES}

\section{Appendix A: Definition and Calculation of Milk Yield Sensor Features}

Table A1 gives the details of the different SF calculated from daily milk yield data included in the prediction models. The iterated theoretical Wood model is the result of the iterative fitting and refitting procedure excluding perturbations to estimate the shape of the theoretical lactation curve. All SF are standardized at herd level before entering them in the models, by $\mathrm{SF}_{\text {standardized }}=\frac{S F-\overline{S F}}{S D(S F)}$, with $\mathrm{SF}$ each sensor feature,

$\overline{S F}$ the average of each SF for a herd, and $S D(S F)$ the standard deviation for that SF for a herd.

\section{Appendix B: Definition and Calculation of Activity Sensor Features}

First, the 2-hourly activity data were aggregated in daily sums. Next, a moving median, using a window of $4 \mathrm{~d}$, was calculated on these daily data time series to identify short spikes associated with estrous behavior (level 1 ; all spikes $>0.4 \times$ the maximal residual of the time series minus the moving median). A moving median of $20 \mathrm{~d}$ was calculated to identify periods with generally lower or higher activity, possibly associated with health events. A threshold of $20 \%$ of the minimal or maximal activity residuals was set to identify these deviating activity periods. Table A2 explains calculated $\mathrm{SF}$ based on the deviations from these median windows. 
Table A1. Lactation sensor features (SF) and their calculation included in the prediction models for lifetime resilience ranking

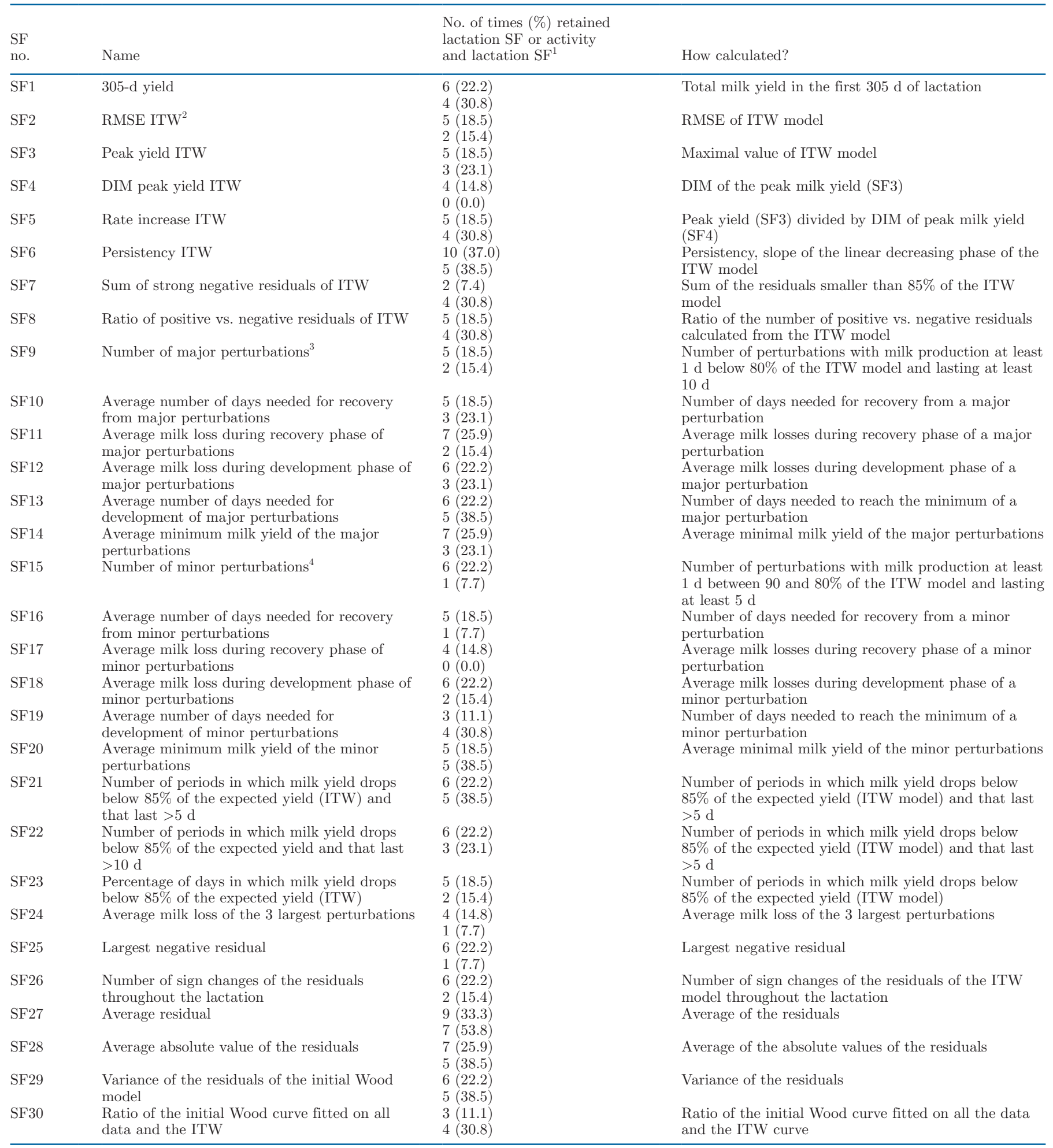

${ }^{1}$ For each SF, we evaluated how often it was retained in the individual farm models of data set 1, using the stepwise selection procedure. The more often a certain SF was retained, the more informative it was for predicting the lifetime resilience ranking of the cows. Data set 1 included 27 farms in total.

${ }^{2} \mathrm{RMSE}=$ root mean squared error; ITW $=$ iterated Wood model.

${ }^{3}$ Major perturbations = periods of at least $10 \mathrm{~d}$ of successively negative residuals with at least $1 \mathrm{~d}$ of milk production lower than $80 \%$ of the theoretical production.

${ }^{4}$ Minor perturbations $=$ periods of at least $5 \mathrm{~d}$ of successively negative residuals with at least $1 \mathrm{~d}$ of milk production between $90 \%$ and $80 \%$ of the expected production. 
Table A2. Activity sensor features (SF) and their calculation included in the prediction models for lifetime resilience ranking

\begin{tabular}{|c|c|c|c|}
\hline $\begin{array}{l}\text { SF } \\
\text { no. }\end{array}$ & Activity feature & $\begin{array}{l}\text { No. of times } \\
(\%) \text { retained }^{1}\end{array}$ & How calculated? \\
\hline SF31 & Daily mean & $6(46.2)$ & Daily mean activity value \\
\hline SF32 & Daily overall skewness & $1(7.7)$ & Skewness of the daily activity time series \\
\hline SF34 & Number of first-level peaks & $11(84.6)$ & $\begin{array}{l}\text { Number of sharp peaks, larger than } 0.4 \text { times the maximal peak } \\
\text { height after correction for } 4 \text {-d median activity level }\end{array}$ \\
\hline SF35 & $\begin{array}{l}\text { Average peak height of first-level } \\
\text { peaks }\end{array}$ & $5(38.5)$ & $\begin{array}{l}\text { Average peak height of peaks larger than } 0.4 \text { times the maximal } \\
\text { peak height after correction for } 4 \text {-d median activity level }\end{array}$ \\
\hline SF37 & DIM of first peak & $8(61.5)$ & $\begin{array}{l}\text { DIM of first peak larger than } 0.4 \text { times the maximal peak height } \\
\text { after correction for } 4 \text {-d median activity level }\end{array}$ \\
\hline SF38 & $\begin{array}{l}\text { Number of periods with higher } \\
\text { activity compared with long-term } \\
\text { median activity }\end{array}$ & $3(23.1)$ & $\begin{array}{l}\text { Number of periods with activity level higher than } 0.2 \text { times the } \\
\text { maximal level compared with long-term } 20 \text {-d median activity level }\end{array}$ \\
\hline SF39 & $\begin{array}{l}\text { Average activity level of periods } \\
\text { with higher activity compared with } \\
\text { long-term median activity }\end{array}$ & $3(23.1)$ & $\begin{array}{l}\text { Average activity level of periods with activity level higher than } \\
0.2 \text { times the maximal level compared with long-term } 20 \text {-d median } \\
\text { activity level }\end{array}$ \\
\hline SF41 & $\begin{array}{l}\text { Duration of periods with higher } \\
\text { activity compared with long-term } \\
\text { median activity }\end{array}$ & $4(30.8)$ & $\begin{array}{l}\text { Duration of periods with activity level higher than } 0.2 \text { times the } \\
\text { maximal level compared with long-term } 20 \text {-d median activity level }\end{array}$ \\
\hline SF42 & $\begin{array}{l}\text { Number of periods with lower } \\
\text { activity compared with long-term } \\
\text { median activity }\end{array}$ & $2(15.4)$ & $\begin{array}{l}\text { Number of periods with activity level lower than } 1.2 \text { times the } \\
\text { minimal level compared with long-term } 20 \text {-d median activity level }\end{array}$ \\
\hline SF 43 & $\begin{array}{l}\text { Average activity level of periods } \\
\text { with lower activity compared with } \\
\text { long-term median activity }\end{array}$ & $3(23.1)$ & $\begin{array}{l}\text { Average activity level of periods with activity level lower than } 1.2 \\
\text { times the minimal level compared with long-term 20-d median } \\
\text { activity level }\end{array}$ \\
\hline SF44 & $\begin{array}{l}\text { Minimal activity level in periods } \\
\text { with lower activity compared with } \\
\text { long-term median activity }\end{array}$ & $0(0.0)$ & $\begin{array}{l}\text { Minimal activity level of periods with activity level lower than } 1.2 \\
\text { times the minimal level compared with long-term 20-d median } \\
\text { activity level }\end{array}$ \\
\hline SF45 & $\begin{array}{l}\text { Duration of periods with lower } \\
\text { activity compared with long-term } \\
\text { median activity }\end{array}$ & $2(15.4)$ & $\begin{array}{l}\text { Duration of periods with activity level lower than } 1.2 \text { times minimal } \\
\text { level compared with long-term } 20 \text {-d median activity level }\end{array}$ \\
\hline
\end{tabular}

${ }^{1}$ For each SF, we evaluated how often it was retained in the individual farm models of data set 2, using the stepwise selection procedure. The more often a certain SF was retained, the more informative it was for predicting the lifetime resilience ranking of the cows. Data set 2 included 13 farms in total. 